\title{
A pesquisa científica no campo da compreensão em leitura: um estudo analítico da produção acadêmica
}

\author{
The scientific research in reading comprehension field: \\ an analytical study of academic production
}

\author{
Ademir Paulo Giraldello \\ Claudia Finger-Kratochvil
}

Universidade Federal da Fronteira Sul - UFFS - Chapecó - Santa Catarina - Brasil

\begin{abstract}
Resumo: Considerando a avaliação da compreensão leitora, existem diversos testes em larga escala. Com os indicadores de instrumentos avaliativos, vêm estatísticas alarmantes. Há, entre os brasileiros, baixos níveis de compreensão e acentuado índice de analfabetismo funcional. Portanto, este trabalho investigou o que a comunicação científica tem compartilhado a respeito da leitura, em especial da compreensão em leitura. Para isso, foram selecionados para análise, por meio da Plataforma Sucupira, 33 periódicos científicos Qualis A1 e A2 com escopos relacionados à leitura. Desse corpus de periódicos, analisaram-se publicações cujo tema se relacionasse à leitura de 2011 a 2015. Os dados indicam, em primeiro lugar, que contribuições da Psicologia têm forte influência na pesquisa em leitura e compreensão. Em segundo, evidenciam que compreensão é a temática mais frequente em produções eletrônicas. Por fim, constata-se que, cada vez mais, se investigam facetas da compreensão acerca das bases neurobiológicas da leitura, bem como há diversas pesquisas que propõem estratégias para melhoria da compreensão em leitura.
\end{abstract}

Palavras-chave: Psicolinguística. Compreensão Leitora. Produção Acadêmica.

\begin{abstract}
Regarding reading comprehension assessments, there are some large scale tests which show tough and alarming statistics to Brazilian community. Numbers unveil low levels of reading comprehension and a significant rate of functional illiteracy. We therefore investigated what scientific communication has shared about reading, focusing on reading comprehension. For this, we selected for analysis, through the Sucupira Platform, 33 scientific journals Qualis A1 and A2 with scopes related to reading. From this corpus of journals, we analyze publications with subject in reading from 2011 to 2015. With the data critical-reflexive appreciation, three main points are unveiled. First, Psychology contributions have strong influence in the reading and comprehension research. Second, comprehension is the most frequent theme studied in electronic productions. Finally, comprehension facets regarding the reading neurobiological bases have been investigated, as well as some research about strategies to improve reading comprehension.
\end{abstract}

Keywords: Psycholinguistics. Reading Comprehension. Academic Production. 


\section{Considerações Iniciais}

A leitura é uma das atividades cognitivas mais sofisticadas que os seres humanos realizam e tem recebido atenção de diversos campos de estudo. Considerando os diferentes papéis que vem assumindo na comunicação humana, além da própria Psicolinguística e Psicolinguística Aplicada, conta com contribuições da Linguística, das Neurociências, da Análise de Discurso, da Psicologia Cognitiva, da Inteligência Artificial, para enumerar algumas das ciências envolvidas nesses estudos. Além disso, durante a execução da tarefa em leitura, são acionados processos cognitivos e linguísticos, que requerem diversas habilidades (ISRAEL; DUFFY, 2017; PEARSON; CERVETTI; 2015; 2017).

Para a avaliação de competências e habilidades em leitura existem diversas modalidades de testes. Considerando o contexto escolar brasileiro, são conhecidos o Programa Internacional de Avaliação de Alunos (Pisa), o Sistema de Avaliação da Educação Básica (Saeb) e o Exame Nacional do Ensino Médio (ENEM). Os resultados desses testes fornecem indicadores que, muitas vezes, revelam estatísticas alarmantes: baixos índices de compreensão e acentuado analfabetismo funcional, tanto na educação básica quanto na superior (FINGER-KRATOCHVIL， 2010; GABRIEL, 2010; HIRSCH, 2003; KLEIMAN, 2011; RODRIGUES, 2013; SOUZA, 2004). Isso indicaria ausência de estudos em compreensão em leitura entre os pesquisadores brasileiros? Buscou-se, então, investigar que temáticas em torno de leitura a comunicação científica tem movimentado e disponibilizado em periódicos eletrônicos, evidenciando eventual lacuna nos estudos já desenvolvidos.

Assim, primeiramente, discute-se a respeito da leitura e de processos relacionados e subjacentes a essa tarefa de processamento de informações textuais. Em seguida, apresentam-se os procedimentos metodológicos adotados para realizar este trabalho de pesquisa. Por fim, apresentam-se os dados resultantes, buscando entender o quadro que se apresenta.

\section{Leitura e compreensão}

$(R e)$ construir a significação de um texto, isto é, compreendê-lo, não é um exercício fácil. O leitor precisa lançar mão de uma série de informações, processos e recursos cognitivos. E como outras tarefas do domínio da cognição, a leitura demanda percepção, atenção, memória(s).

É consenso na comunidade científica que a compreensão é o objetivo central da leitura. Em outras palavras, é necessário que o leitor seja capaz de construir uma representação mental a respeito do que lê e, para isso, vários processos cognitivos precisam ser desencadeados e realizados com acuidade. Morais (2013) destaca que a leitura envolve mais do que o processo de decodificação, certamente, mas não pode ser apenas entendida como a compreensão daquilo que se lê. Muitos são os processos (e subprocessos) envolvidos, linguísticos e cognitivos, que necessitam interagir uns com os outros para que essa atividade cognitiva complexa se efetive.

Sendo assim, pode-se chegar a um conceito síntese de leitura. A leitura é o processo interativo de (re)construção da significação textual que tem amparo na utilização do conhecimento prévio - os (extra)linguísticos, (meta)cognitivos e (inter)textuais. O processo de leitura inicia-se com a decodificação grafêmico-fonológica, envolve diversas habilidades (meta)cognitivas e culmina com a compreensão leitora. O esforço bem-sucedido de (re)construção da significação textual caracteriza a compreensão (KATO, 2007; KLEIMAN, 2009, 2011, 2012; MORAIS, 2013; SOUZA, 2012; SOLÉ, 1998; SPINILLO; MOTA; CORREA, 2010).

O início da reconstrução da significação de um texto envolve processamento de base das habilidades em leitura (low level): a decodificação. A decodificação é o processo de relacionar um grafema a um determinado fonema correspondente (SCLIARCABRAL, 2012). Quando os leitores aprendem que grafemas representam fonemas, entendem 0 chamado princípio alfabético e estão desenvolvendo 
a consciência fonêmica que Ihes permitirá avançar no desenvolvimento das habilidades da leitura.

À medida que decodifica o texto, o leitor faz o reconhecimento de palavras. Essa tarefa é bemsucedida em função de ele acessar seu léxico, dicionário mental, do qual recupera informações ortográficas, fonológicas, semânticas, sintáticas, pragmáticas de seus itens (SOUSA; GABRIEL, 2012).

O acesso lexical (processo de criação, identificação e recuperação de informações de palavras no léxico) é explicado, como apontam Salles e Parente (2002), por três principais modelos. No Modelo de Leitura de Rota Lexical, o acesso é direto, por meio da visão. Vê-se uma palavra (conhecida) e, imediatamente, recuperam-se suas informações do léxico por meio de associação direta de uma forma escrita a seu significado essencial. No Modelo de Leitura de Rota Fonológica (procedimento gerativo essencial na aprendizagem da leitura), o acesso se dá de maneira indireta, por intermédio da fonologia. Há a conversão de grafemas em fonemas (decodificação). Com isso, criam-se pronúncias para a palavra (des)conhecida. Por outro, adquirese/constrói-se conhecimento (processo bottom-up) de diversos níveis sobre ela por meio de informações textuais (SCLIAR-CABRAL, 2008). Feito isso, a palavra e o conhecimento sobre ela são armazenados no léxico. Há também o Modelo de Leitura de Rota Dupla, identificado no leitor proficiente. Aquele que se vale da dupla rota reconhece palavras tanto pela visão quanto pela fonologia. A competência leitora e o input linguístico, como palavras (des)conhecidas e (ir)regulares, determinam mais o uso de uma ou outra rota. Sendo assim, torna-se evidente que a aprendizagem é, sim, analítica e não global (SCLIARCABRAL, 2008).

Os processos de leitura supracitados são amparados por uma competência cognitiva geral, a memória. Conforme Sternberg (2010), a memória é a maneira pela qual se retém e se vale de experiências passadas para utilizá-las no presente. São de responsabilidade da memória a aquisição, a manutenção e a recuperação de informações (IZQUIERDO, 2002). Logo, a capacidade de memória é extremamente relevante e relacionada à leitura. Da mesma maneira, a memória é um componente essencial na compreensão, visto que é por meio dela que se manipulam informações do input socioambiental e, também, as que ela já dispõe (armazenadas). Além disso, a memória é relevante à leitura porque o conhecimento que ela já tem armazenado influencia tanto na aquisição de novas informações (nesse caso, aprendizagem) quanto na sua organização e na sua evocação posterior.

Com relação à compreensão textual, os trabalhos de Kintsch e van Dijk (1978), junto a outros (e.g., SWEET; SNOW, 2003), são de grande relevância. Conjuntamente, os primeiros autores desenvolveram um consistente modelo psicológicolinguístico de processamento do texto, que presume que, na compreensão, uma série de processos ocorre em paralelo ou sequencialmente.

Nesse modelo, o texto é concebido como um conjunto de proposições ${ }^{1}$, umas explicitamente expressas outras subentendidas (KINTSCH; VAN DIJK, 1978). Compreendê-lo significa representar gradual e mentalmente em redes semânticas as proposições textuais. Para haver compreensão, em primeira instância, o leitor faz o reconhecimento de palavras, com base na decodificação do texto. Com isso, ele recupera aspectos fonológicos e semânticos dos vocábulos. Ou seja, nessa etapa, a compreensão inicia-se com processos bottom-up (ascendentes), por meio do acesso lexical. Posteriormente, os significados individuais das palavras de um período são combinados na memória de trabalho ${ }^{2}$, formandose uma proposição (KINTSCH, 1988).

Ressalta-se que a estrutura semântica do texto é caracterizada pela micro e macroestrutura. A

\footnotetext{
1 Proposições são unidades abstratas de significado de um texto (KINTSCH, 1988). Psicologicamente, proposição é a representação conceitual de uma sentença na mente do leitor.

2 A memória de trabalho (working memory) é um modelo de memória proposto por Alan Baddeley e Graham Hitch em 1974. Esse modelo supera a memória de curto prazo do modelo tradicional de Atkinson e Shiffrin de 1968. A memória de trabalho é um sistema multicomponencial formado por quatro estruturas básicas: um componente chefe e três auxiliares. Esses componentes são, segundo Baddeley (2000), o executivo central (central executive), o circuito fonológico (phonological loop), o esboço visuoespacial (visuospatial sketchpad) e o retentor episódico (episodic buffer). Para maiores esclarecimentos, sugerimos a leitura de Baddeley (2012).
} 
microestrutura textual contém proposições individuais, com informações específicas sobre o texto (isto é, microproposições). Já a macroestrutura textual contém proposições genéricas, com informações gerais sobre o texto (ou seja, macroproposições). As proposições (em nível micro e macro) relacionam-se. Essa relação se dá por meio de macrorregras (macrorules) - regras específicas de mapeamento e redução semântica. Logo, a utilização de macrorregras auxilia o leitor na triagem de informações textuais para constituir sua coerência global (KINTSCH; VAN DIJK, 1978).

As principais regras são 0 apagamento (deletion), a generalização (generalization), a construção (construction). Ou seja, excluem-se da macroestrutura textual [mas não da memória] proposições menos relevantes para uma tarefa de leitura e/ou redundantes e que não são úteis para a interpretação de outras proposições); unem-se proposições textuais a partir do que lhes é comum; constroem-se proposições com base em proposições do texto, respectivamente. Destaca-se que "Macrooperadores [isto é, macrorregras] transformam as proposições de uma base textual em um conjunto de macroproposições que representam a essência [semântica] do texto. Eles [os macro-operadores] fazem isso apagando ou generalizando todas as proposições que são irrelevantes ou redundantes e construindo novas proposições inferidas." (KINTSCH; VAN DIJK, 1978, p. 372, tradução nossa) ${ }^{3}$. Desse modo, macro-operadores têm como função reduzir as informações textuais à macroestrutura do texto. Os macro-operadores são controlados por objetivos do leitor para com uma determinada leitura. Sendo assim, há a possibilidade de inclusão de uma ou outra proposição (tanto micro quanto macro) à macroestrutura do texto.

Além disso, inter-relacionando as proposições micro e macroestruturais de um texto, o leitor chega à base textual (KINTSCH; FRANZKE, 1995). Ou seja, a micro e a macroestrutura formam a base textual (text

\footnotetext{
3 "Macro-operators transform the propositions of a text base into a set of macropropositions that represent the gist of the text. They do so by deleting or generalizing all propositions that are either irrelevant or redundant and by constructing new inferred propositions." (KINTSCH; VAN DIJK, 1978, p. 372)
}

base). Logo, a base do texto é sua significação fundamentada em elementos do próprio texto - o input linguístico, isto é, uma sequência coerente de proposições.

À medida que se compreende um texto, suas unidades são transformadas em representações mentais (KINTSCH; FRANZKE, 1995). E ao se construir uma base textual, em certa medida pode-se entender que há construção de compreensão leitora. No entanto, como ela consiste basicamente em informações fornecidas pelo texto, apresenta limites. Então, para que a compreensão ocorra em níveis mais altos, ao passo que se constrói a base do texto, pressupõe-se a ativação de informações da memória de longo prazo relacionadas à situação descrita no texto (KINTSCH, 1988). Essas informações nada mais são do que representações cognitivas que se tem de eventos, pessoas, contextos, ações; enfim, conhecimento armazenado, que pode ser utilizado para se fazer inferências e preencher lacunas existentes no texto. Dessa forma, entende-se que a compreensão também depende de processos descendentes (top-down). Por fim, integrando os pontos essenciais do texto (macroproposições) ao conhecimento prévio do leitor, constrói-se mentalmente um modelo da situação (situation model).

Por conseguinte, em relação à compreensão textual, van Dijk e Kintsch (1983, p. 11, tradução nossa) afirmam que ela "[...] envolve não somente a representação de uma base textual na memória episódica, mas, também, ao mesmo tempo, a ativação, atualização e outros usos do chamado modelo situacional na memória episódica [...]." Dessa forma, para compreender suficientemente um texto, o leitor tem de, além de (i) representar proposicional e mentalmente as principais ideias textuais, (ii) ativar, por meio da memória de trabalho, informações relacionadas à situação do texto da memória de longo prazo. Com isso, o leitor constrói um modelo situacional do texto, que é armazenado junto à

\footnotetext{
4 "[...] involves not only the representation of a text base in episodic memory, but, at the same time, the activation, updating, and other uses of a so-called situation model in episodic memory [...]." (VAN DIJK; KINTSCH, 1983, p. 11)
} 
estrutura cognitiva do leitor. Assim, a compreensão requer a representação mental de unidades semânticas globais de um texto (macroproposições). Essa representação, por fim, é unitária, abrangendo duas partes: a base textual e respectivo modelo situacional.

Com essa explicitação, evidencia-se que leitor se vale de uma série de informações (visuais e não visuais) para reconstruir a significação de um texto, ou seja, para compreendê-lo. O resultado da compreensão são representações mentais. Portanto, quando se afirma que se compreendeu um texto, significa, teoricamente, que ele teve sua significação reconstruída e, por fim, representada mentalmente. Esse processo de representação passa pela apreciação de significados de palavras, sentenças e parágrafos e suas inter-relações, bem como a integração desses processos ao que já se tem armazenado a respeito das questões abordadas no texto.

Em síntese, nessa perspectiva, a compreensão se configura em um processo de (i) interpretação da linguagem escrita (decodificação), de (ii) resumo de ideias principais de um texto (macroproposições), de (iii) ativação de conhecimento prévio e de (iv) representações mentais das unidades semânticas desse texto. Ressalta-se que há a integração - às vezes alteração, complementação ou eliminação - de informações na estrutura cognitiva do leitor por ocasião dos processos de compreensão e construção de representações mentais. Por conseguinte, a decodificação possibilita a compreensão. E a compreensão textual é a finalidade da leitura, mesmo variando os propósitos a cada leitura - e.g., leitura por prazer, leitura para aprender, leitura pelo prazer de aprender. Logo, ler, de um lado, depende de uma série de informações e conhecimentos, sendo que se vale do que já se sabe para compreender algo e, de outro, aprender o que se desconhece.

\section{Procedimentos Metodológicos}

Este estudo tem por objetivo, considerando a abordagem psicolinguística de investigação da leitura, conhecer as pesquisas cuja temática evidenciada da comunicação eletrônica é recorrente no campo da leitura. Para que essa proposta se efetivasse, três etapas elementares de pesquisa foram necessárias mapeamento dos periódicos, categorização e seleção e, por fim, estudo do corpus - que somadas, ao final, propiciaram os subsídios teórico-práticos para os resultados ora apresentados. Detalha-se essa trajetória a seguir.

Em primeiro lugar, mapearam-se os periódicos eletrônicos com Qualis A1 e A2 na área de (a) Letras/Linguística, (b) Psicologia e (c) Educação, com base no sistema WebQualis ${ }^{5}$ da Capes, delimitando aqueles com foco e escopo relacionados diretamente com o campo da leitura, a fim de analisar quanti e qualitativamente seus artigos. A título de esclarecimento, periódicos com estratos A1 e A2 foram selecionados como suporte de coleta de dados justamente por serem os veículos da comunicação científica com a mais elevada qualidade aferida pela Capes. Assim, optou-se pelo WebQualis por ser um sistema que inventaria e avalia, de tempo em tempo (i.e., regularmente), periódicos cujo algum artigo seja de autoria de um pesquisador ligado a um programa da pós-graduação brasileira.

O princípio da pesquisa prática, por conseguinte, correspondeu ao acesso no WebQualis. Com ele, mapeou-se a totalidade de periódicos científicos, tanto os impressos quanto os eletrônicos, em cada uma das três áreas selecionadas, ou seja, as que mantêm maior aproximação de abordagem com a temática de pesquisa.

Posteriormente, com a identificação da totalidade de periódicos científicos, utilizou-se o Portal de Periódicos da Capes. Com os dados do WebQualis, acessaram-se todos os periódicos

\footnotetext{
5 Para esclarecimento, dia 23 de março de 2014, houve lançamento de uma nova forma de compartilhamento externo de dados do SNPG - a Plataforma Sucupira. Projetada desde 2012 pela Capes e pela Universidade Federal do Rio Grande do Norte (UFRN), recebeu este nome para homenagear Newton Lins Buarque Sucupira, autor do Parecer no 977 (1965), que configurou a pós-graduação brasileira. A Plataforma Sucupira engloba atividades de coleta de dados de programas de pósgraduação brasileiros (antes a cargo do Sistema de Coleta de Dados) e divulgação externa de informações de avaliações (antes a cargo do WebQualis). Ou seja, a Plataforma Sucupira corresponde à integração de alguns dos módulos que a Capes já dispunha.
} 
registrados para se poder fazer uma primeira categorização deles: os impressos e os eletrônicos. A partir dos dois grupos formados, passou-se à etapa da pesquisa apenas com os periódicos eletrônicos. Com base nesse conjunto, os focos e escopos de cada um foram observados. O primeiro olhar funcionou como um filtro qualitativo-restritivo, tendo como objetivo fazer a exclusão de periódicos que não publicaram artigos científicos no domínio da leitura porque não mantêm relação direta com ela. Da análise do foco e do escopo de todos os periódicos eletrônicos registrados no WebQualis em Letras/Linguística, Psicologia e Educação, permaneceram, para constituir o corpus desta pesquisa, apenas os (i) eletrônicos e (ii) com foco e escopo relacionados diretamente à leitura na perspectiva psicolinguística.

Em terceiro lugar, para se poder evidenciar as temáticas mais recorrentes na comunicação científico-eletrônica, foi preciso identificar artigos científicos que abordassem a leitura em nível linguístico-cognitivo, publicados nos periódicos delimitados pelo foco/escopo, das três áreas contempladas, por meio de análise de todos os volumes e números desses periódicos, inclusive de edições especiais, de 2011 a 2015, colhendo seus resumos com o intuito de avaliar quantitativamente as temáticas mais recorrentes em torno de leitura.

O período sob análise compreende os anos de 2011 a 2015, observando-se que quando a coleta de dados ocorreu, em 2015, o ano estava em curso. Portanto, alguns periódicos ainda estavam organizando volumes e números para publicação. Desse modo, esclarece-se que os dados coletados compreendem de janeiro a agosto de 2015. Em suma, o período cronológico considerado para as discussões é de 54 meses de publicação para se analisarem tendências de temáticas de trabalhos com tema em leitura.

A identificação de artigos foi realizada por meio de palavras-chave em relação ao corpus de periódicos eletrônicos com focos e escopos relacionados à leitura. Detalhando, com dados fornecidos pelo WebQualis de identificação dos periódicos selecionados, acessamos cada um deles no Portal de Periódicos Capes. No sistema de busca dos periódicos, digitamos 'leitura' e 'ler' e seus respectivos equivalentes em algumas outras línguas, tais como o espanhol, francês, alemão, e principalmente considerando a língua inglesa, visto que a maior parte de informações virtuais se encontra escrita nessa língua. Integraram, portanto, o corpus de artigos científico-eletrônicos os que possuíam em seu título a palavra 'leitura' e/ou 'ler' e aqueles com essas palavras equivalentes em línguas estrangeiras. Para a recuperação de artigos cujo tema fosse leitura, houve fechamento das buscas no título e por meio da palavra-chave "leitura/ler".

Entende-se que a triagem feita por meio desse filtro não é exaustiva. Certamente, não foram recuperados todos os artigos que abordaram a leitura em nível linguístico-cognitivo, até porque nem todos os artigos cujo tema fosse leitura possuíam em seu título a palavra 'leitura' ou 'ler'. Contudo, esse foi um critério metodológico definido que possibilitou a organização, apreciação e efetivação da proposta desta pesquisa.

Por fim, com as etapas de pesquisa anteriores finalizadas, foi possível evidenciar, com base nos filtros metodológicos, temáticas da produção científica frequentes na área de leitura em âmbito psicolinguístico (tendências), bem como integrar qualitativamente resultados de artigos eletrônicos de pesquisas independentes em torno da temática mais recorrente, e, por conseguinte, elaborar uma síntese. Para determinar tendências, isto é, temáticas em leitura mais recorrentes na comunicação eletrônica, houve apreciação dos resumos e das palavras-chave dos artigos mapeados. Primeiramente, de cada artigo, analisou-se o objetivo de pesquisa apresentado no resumo e o tema de pesquisa representado por uma das palavras-chave do resumo. Do balanço desses dois itens, definiu-se um vocábulo ou uma locução como temática para o artigo. Ela, portanto, poderia ser uma palavra-chave apresentada no resumo ou termo definido pelos pesquisadores. Pelo aspecto de recorrência de um determinado tema em diversos artigos, pôde-se definir categorias. Assim, as mais 
frequentes em artigos corresponderam às tendências temáticas da produção científica no campo de leitura.

Passou-se à última etapa: sintetizar o conhecimento eletrônico da temática em leitura mais recorrente, por meio da análise integral dos artigos eletrônicos em que ela se fez presente. Com esse percurso, tem-se um balanço acerca de pesquisas e estudos mais recorrentes, realizados em torno da leitura em publicações de periódicos eletrônicos, bem como uma síntese e algumas reflexões a respeito dessas investigações. Portanto, combinaram-se os resultados eletrônicos de pesquisas independentes para analisar o status da pesquisa desse tópico. A seguir, explicitam-se e justificam-se os critérios de inclusão e exclusão de periódicos e artigos para a composição dos corpora.

\subsection{Critérios de seleção e exclusão de periódicos científicos}

Após a seleção das três áreas supracitadas, definimos o corpus de periódicos para investigação. Esta pesquisa privilegiou a apreciação de publicações eletrônicas, sendo excluídos periódicos publicados em formato impresso. Por não se restringir à análise de periódicos científicos brasileiros, a reunião de periódicos impressos para apreciação tornaria inviável a efetivação dos objetivos, principalmente quando considerados os internacionais, considerando limitações de recursos financeiros e restrições para a coleta de dados. Consequentemente, esses fatores interfeririam na concretização da pesquisa. Também, excluíram-se periódicos cujos focos e escopos têm relação fechada e direta com áreas como Literatura, Análise de Discurso, Psicologia Social, Gestão Escolar, dentre outras, que não contemplam a leitura a partir do viés linguístico-cognitivo.

Integraram o corpus de periódicos, portanto, os de formato eletrônico. Optou-se pelos eletrônicos porque a utilização do Portal Capes viabiliza a coleta de dados de periódicos científicos quando se trata de apreciação de centenas/dezenas deles. Também, porquanto os periódicos eletrônicos, quando comparados aos impressos, têm melhor difusão e visibilidade, especialmente no contexto acadêmico devido à possibilidade de acesso.

Igualmente, selecionaram-se dos periódicos eletrônicos aqueles que possuem focos e escopos relacionados diretamente com o campo de leitura na perspectiva linguístico-cognitiva. Ou seja, foram incluídos aqueles que têm relação com áreas como a Psicolinguística, Psicologia Cognitiva, Neurociência, Letras, Linguística, que se atêm, de modo (in)direto, ao processo de (re)construção da significação textual, bem como a aspectos subjacentes à leitura.

\subsection{Critérios de seleção e exclusão de artigos científicos}

Depois de definido o corpus de periódicos eletrônicos, constituiu-se o de artigos científicos. Primeiramente, foram excluídos aqueles que apresentavam como foco discussões da leitura no viés discursivo, literário ou outra área que não abarcasse os aspectos linguístico-cognitivos da leitura.

Elegeram-se para constituir o corpus artigos cujos títulos continham o vocábulo 'leitura' ou, secundariamente, 'ler'. O motivo desse procedimento metodológico foi criar dois filtros para recuperação de trabalhos em leitura. Primeiro, optou-se por essas palavras-chave visto que configuram o assunto desta investigação. Outras poderiam modificar os resultados, enviesando-os. Esclarece-se que, considerando as línguas detectadas pelos nomes dos periódicos científicos mapeados, além das palavras 'leitura' e 'ler', utilizaram-se termos correlatos de outras línguas, tais como 'reading' e 'to read' para o inglês, 'lectura' e 'leer' para o espanhol, 'lecture' e 'lire’ para o francês, 'lesen' e 'lesen' para o alemão. E, em segundo, definiu-se apreciar apenas os artigos com tais palavras-chaves se encontradas em seu título. A fim de que isso funcionasse como um filtro quanti-qualitativo, isto é, restringisse as buscas: não se teve como foco exaurir a recuperação de estudos/pesquisas relacionadas à leitura, mas, sim, constituir um corpus significativo para análise e efetivação de um objetivo maior. 
Para a definição de temáticas mais recorrentes em leitura na comunicação científico-eletrônica, os artigos não foram analisados integralmente; somente seus resumos e palavras-chave. Em alguns casos de resumo pouco claros, recorreu-se ao artigo completo. Justifica-se a seleção de resumos dos artigos científicos e não dos próprios artigos, em primeiro lugar, visto que a apreciação de artigos integrais demandaria substancial tempo, considerando as centenas recuperadas. Em segundo, porque resumos de artigos científicos são, em sua maioria, do tipo informativo/analítico, aquele que contém informações principais apresentadas no texto, salientando a temática, objetivos, metodologia, resultados.

Em suma, apresentou-se o passo a passo metodológico definido para que se atingissem os objetivos propostos. Na próxima seção, revisa-se o percurso de investigação e apresentam-se os dados sistematizados, analisando-os de uma perspectiva crítico-reflexiva.

\section{Resultados e discussão}

Esta pesquisa ocorreu em 2015. Dessa forma, o inventário de periódicos registrados e avaliados compreendeu o triênio 2010-2011-2012 pelo WebQualis (2015) e dados do próximo período, que passou a ser em quadrienal (2013-2014-2015-2016), ainda estando em sistematização naquele momento.
Houve alterações no processo de coleta de dados, os quais são informados pelas Instituições de Ensino Superior - IES em fluxo contínuo. Todos os dados da produção acadêmica de pessoas integradas a cursos stricto sensu do Sistema Nacional de Pós-Graduação - SNPG do Brasil, dentre outros, são coletados pela Capes por meio do Módulo Coleta de Dados da Plataforma Sucupira, e as informações são compartilhadas pelo Módulo Consulta (antes designado de WebQualis).

Com dados do WebQualis (2015), procedeu-se a catalogação da totalidade de periódicos registrados no sistema, que abrangem os impressos/eletrônicos de 48 áreas de avaliação. Para isso, acessou-se uma lista que é disponibilizada para download. Os dados foram sistematizados e podem ser analisados na Figura 1.

Em relação à Figura 1, destaca-se que o total de 108.555 periódicos inventariados é inferior na prática, pois um mesmo periódico pode, no processo de classificação, ser incluído em mais de uma das 48 áreas de avaliação da Capes. Da análise, ao se considerar os estratos A1, A2, B1, B2, aproximadamente 51.607 periódicos (47,53\%) têm significativa relevância para suas áreas e impactamnas significativamente. Além disso, evidencia-se que o estrato com menor número de periódicos incluídos é o A1 (8.470 periódicos). Esse fato é explicado pelo

Figura 1 - Total de 108.555 periódicos científicos registrados pelo

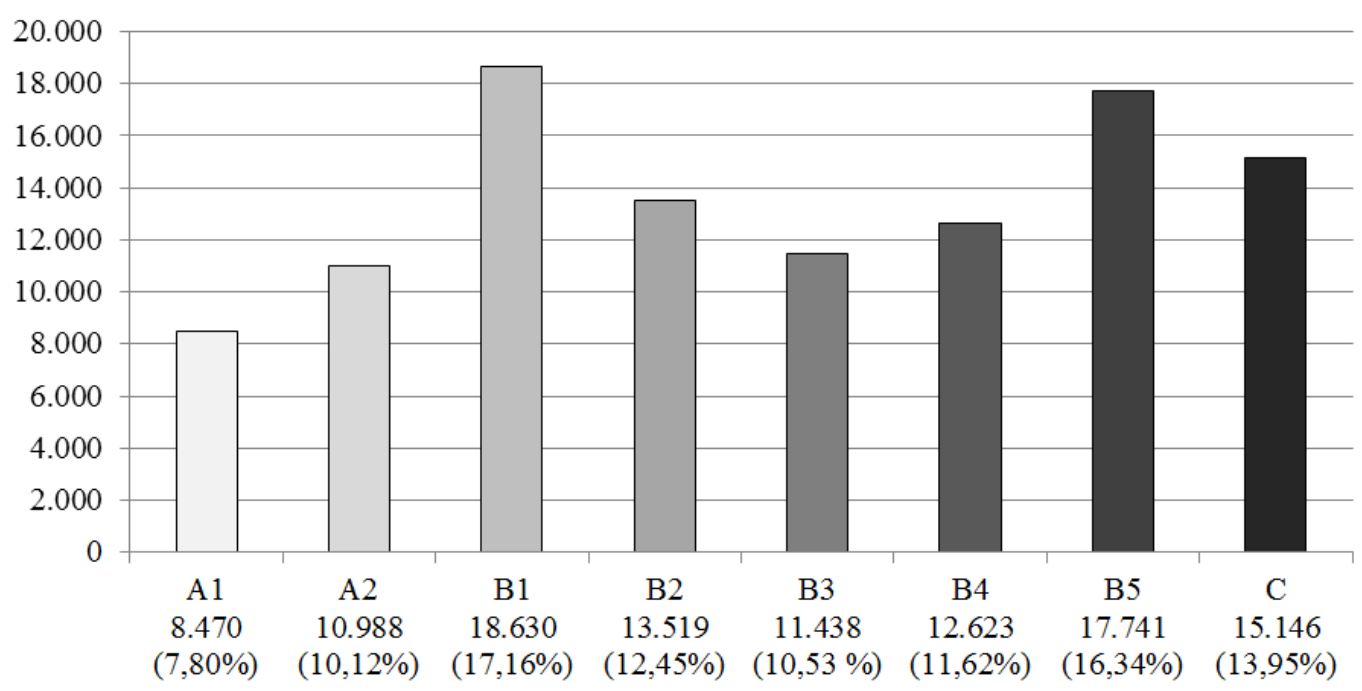

Fonte: os autores 
rigor de critérios requerido de um periódico para que ele receba determinado Qualis. Outro dado que chama a atenção é o número de periódicos com classificação C. Isso significa que 15.146 periódicos avaliados no triênio 2010-2012 não se enquadraram nos parâmetros e critérios exigidos nos outros estratos (A1, A2, B1, B2, B3, B4, B5).

A quantidade de periódicos registrada no WebQualis (2015) correspondente ao triênio 20102012 foi de 108.555. O foco da análise desses periódicos restringiu-se aos inclusos nas áreas Letras/Linguística, Psicologia e Educação (as três mais diretamente relacionadas à leitura) e apenas os que fossem apresentados em formato eletrônico, com Qualis A1 e A2. Assim, desses 108.555, 8.470 foram classificados com Qualis A1 e 10.988 com Qualis A2. Dos 8.470 periódicos $A 1,120$ estão inclusos na área de Letras/Linguística, 123 na de Psicologia e 114 na de Educação. Dos 10.988 periódicos A2, 139 estão inclusos na área de Letras/Linguística, 327 na de Psicologia e 169 na de Educação. Dos 259 periódicos A1 (120) e A2 (139) de Letras/Linguística, selecionaram-se apenas 15 (eletrônicos e com foco/escopo relacionado à leitura). Dos 450 periódicos A1 (123) e A2 (327) de Psicologia, 15 somente foram selecionados. E, dos 283 periódicos A1 (114) e A2 (169) de Educação, três foram escolhidos. Portanto, o corpus para que a pesquisa se concretizasse foi um grupo de 33 periódicos eletrônicos com foco e escopo relacionados à leitura. Em relação a dados nominais e algumas informações a respeito desses 33 periódicos eletrônicos selecionados, observe-se o Quadro 1.

Quando 1: Relação do corpus de 33 periodicos eletrônicos relacionados à leitura.

\begin{tabular}{|c|c|c|c|}
\hline \multicolumn{4}{|c|}{ Periódicos eletrônicos na área de Letras/Linguística } \\
\hline \multicolumn{2}{|c|}{ ISSN } & NOME & FSTRATO \\
\hline 1 & $\begin{array}{l}1981- \\
5794\end{array}$ & $\begin{array}{l}\text { Alfa: Revista de } \\
\text { Linguística }\end{array}$ & A1 \\
\hline 2 & $\begin{array}{l}1450- \\
3417\end{array}$ & Biolinguistics & A1 \\
\hline 3 & $\begin{array}{l}0102- \\
5767\end{array}$ & $\begin{array}{c}\text { Cadernos de Estudos } \\
\text { Linguísticos }\end{array}$ & A1 \\
\hline 4 & $\begin{array}{l}1678- \\
460 x\end{array}$ & $D E L T A$ & A1 \\
\hline
\end{tabular}

\begin{tabular}{|c|c|c|c|}
\hline 5 & $\begin{array}{l}1535- \\
0665\end{array}$ & Language & $\mathrm{A} 1$ \\
\hline 6 & $\begin{array}{l}1984- \\
7726\end{array}$ & Letras de Hoje & $\mathrm{A} 1$ \\
\hline 7 & $\begin{array}{l}1982- \\
7830\end{array}$ & Revista da ANPOLL & $\mathrm{A} 1$ \\
\hline 8 & $\begin{array}{l}2237- \\
2083\end{array}$ & $\begin{array}{c}\text { Revista de Estudos da } \\
\text { Linguagem }\end{array}$ & $\mathrm{A} 1$ \\
\hline 9 & $\begin{array}{l}1984- \\
6398 \\
\end{array}$ & $\begin{array}{l}\text { Revista Brasileira de } \\
\text { Linguística Aplicada }\end{array}$ & $\mathrm{A} 1$ \\
\hline 10 & $\begin{array}{l}1983- \\
4683 \\
\end{array}$ & $\begin{array}{c}\text { Acta Scientiarum - } \\
\text { Language and Culture }\end{array}$ & $\mathrm{A} 2$ \\
\hline 11 & $\begin{array}{l}2177- \\
6202\end{array}$ & Calidoscopio & $\mathrm{A} 2$ \\
\hline 12 & $\begin{array}{l}1984- \\
591 X\end{array}$ & Revista do GEL & $\mathrm{A} 2$ \\
\hline 13 & $\begin{array}{l}1983- \\
2400 \\
\end{array}$ & $\begin{array}{c}\text { Revista Linguagem \& } \\
\text { Ensino }\end{array}$ & $\mathrm{A} 2$ \\
\hline 14 & $\begin{array}{l}2237- \\
4876 \\
\end{array}$ & $\begin{array}{c}\text { Signum: Estudos da } \\
\text { Linguagem }\end{array}$ & $\mathrm{A} 2$ \\
\hline 15 & $\begin{array}{l}1982- \\
2243 \\
\end{array}$ & Veredas & $\mathrm{A} 2$ \\
\hline
\end{tabular}

Periódicos eletrônicos na área de Psicologia

\begin{tabular}{|c|c|c|c|}
\hline \multicolumn{2}{|c|}{ ISSN } & \multirow{2}{*}{$\begin{array}{c}\text { NOME } \\
\text { Acta Psychologica }\end{array}$} & \multirow{2}{*}{$\begin{array}{c}\text { ESTRATO } \\
\mathrm{A} 1\end{array}$} \\
\hline 1 & $\begin{array}{l}0001- \\
6918 \\
\end{array}$ & & \\
\hline 2 & $\begin{array}{l}1695- \\
2294\end{array}$ & Anales de Psicología & A1 \\
\hline 3 & $\begin{array}{l}1469- \\
7610\end{array}$ & $\begin{array}{c}\text { Journal of Child } \\
\text { Psychology and } \\
\text { Psychiatry }\end{array}$ & A1 \\
\hline 4 & $\begin{array}{l}0028- \\
3932\end{array}$ & Neuropsychologia & A1 \\
\hline 5 & $\begin{array}{l}1982- \\
4327\end{array}$ & Paidéia & $\mathrm{A} 1$ \\
\hline 6 & $\begin{array}{l}1678- \\
7153\end{array}$ & $\begin{array}{c}\text { Psicologia: Reflexão e } \\
\text { Crítica }\end{array}$ & A1 \\
\hline 7 & $\begin{array}{l}0270- \\
6474\end{array}$ & $\begin{array}{l}\text { The Journal of } \\
\text { Neuroscience }\end{array}$ & A1 \\
\hline 8 & $\begin{array}{l}0278- \\
2626\end{array}$ & Brain and Cognition & A2 \\
\hline 9 & $\begin{array}{l}0093- \\
934 X\end{array}$ & Brain and Language & $\mathrm{A} 2$ \\
\hline 10 & $\begin{array}{l}0006- \\
8993\end{array}$ & Brain Research & A2 \\
\hline 11 & $\begin{array}{l}0306- \\
4522 \\
\end{array}$ & Neuroscience & A2 \\
\hline 12 & $\begin{array}{l}1980- \\
8623\end{array}$ & Psico & A2 \\
\hline 13 & $\begin{array}{l}2152- \\
7199\end{array}$ & Psychology & $\mathrm{A} 2$ \\
\hline 14 & $\begin{array}{l}1983- \\
3288\end{array}$ & $\begin{array}{l}\text { Psychology \& } \\
\text { Neuroscience }\end{array}$ & $\mathrm{A} 2$ \\
\hline 15 & $\begin{array}{l}1980- \\
6906\end{array}$ & $\begin{array}{c}\text { Revista de Psicologia: } \\
\text { Teoria e Prática }\end{array}$ & $\mathrm{A} 2$ \\
\hline \multicolumn{4}{|c|}{ Periódicos eletrônicos na área de Educação } \\
\hline \multicolumn{2}{|c|}{ ISSN } & NOME & ESTRATO \\
\hline 1 & $\begin{array}{c}0360- \\
1315 \\
\end{array}$ & $\begin{array}{c}\text { Computers and } \\
\text { Education }\end{array}$ & A1 \\
\hline
\end{tabular}




\begin{tabular}{|c|c|c|c|}
\hline 2 & $\begin{array}{c}2175- \\
6236\end{array}$ & Educação e Realidade & A1 \\
\hline 3 & $\begin{array}{c}1808- \\
656 X\end{array}$ & Desenredo & A2 \\
\hline
\end{tabular}

Fonte: os autores

Conforme se mencionou, depois de mapear esses periódicos, foram analisados artigos publicados de janeiro de 2011 a agosto de 2015, englobando todos os volumes e números, de cada um dos 33 . Identificaram-se os artigos eletrônicos que possuíam em seu título a palavra-chave 'leitura' ou 'ler' e seus respectivos equivalentes nas línguas estrangeiras consideradas.

Com essa etapa de pesquisa, 224 artigos foram recuperados: 37 veiculados em periódicos de Letras/Linguística, 26 em Educação e 161 em Psicologia, conforme Quadro 2. Evidencia-se o domínio da área da Psicologia em relação à investigação da leitura e compreensão. Como ambas as tarefas de processamento envolvem e demandam diversas habilidades e processos cognitivos, a área tem vasto leque de estudo e pesquisa, principalmente quando se consideram os aspectos neurobiológicos da leitura.

Analisando o Quadro 2, percebe-se que publicações cuja a temática é leitura têm aumentado no decorrer dos anos. Do todo, 87 das publicações situam-se em 2014-2015, ou seja, em 19 meses, dois terços do que se publicou entre 2011 e 2013. Outro dado que chama a atenção é a quantidade de artigos com tema em leitura publicados por periódicos avaliados na área de Psicologia.
A área tem se voltado para a questão $\mathrm{e}$ contribuído para o progresso do conhecimento sobre a ciência da leitura.

Após o mapeamento dos 33 periódicos eletrônicos com foco e escopo relacionado à leitura e a identificação de 224 artigos com assunto leitura, houve a necessidade de evidenciar as temáticas mais recorrentes nesse corpus. Passou-se, assim, a analisar os resumos dos artigos, observando-se 0 objetivo da pesquisa informado e as palavras-chave enumeradas. Dessa forma, para cada um dos 224 resumos, se elegeu um termo ou locução das palavras-chave do resumo para funcionar como temática. Finalizada essa etapa, contabilizaram-se os resumos que apresentavam a mesma a temática e criaram-se categorias, apresentadas na Tabela 1.

Como se pode constatar, dos 224 artigos eletrônicos mapeados, 22 tratam de algum dos múltiplos componentes da compreensão em leitura. Outros 18 abordam o funcionamento cerebral em relação à leitura. $O$ processo de leitura em bilíngues é tema de 16 artigos. Dividem o mesmo quantitativo, ou seja, 15 artigos cada uma, as áreas de investigação relacionadas à leitura e ao letramento, e à leitura e desenvolvimento de avaliação de diferentes aspectos didático-metodológicos no seu processo ensinoaprendizagem. O reconhecimento da palavra, 14 artigos, é outro tema que reflete a atenção dos pesquisadores, bem como a avaliação em leitura, com 13 artigos. Os outros temas voltam-se à atenção

Quadro 2 - Distribuição dos 224 artigos científicos pelas áreas e anos de investigação

\begin{tabular}{|c|c|c|c|c|c|c|c|c|c|c|c|}
\hline \multirow{3}{*}{ ÁREAS } & \multicolumn{10}{|c|}{ PERÍODO DE ANÁLISE } & \multirow{3}{*}{$\begin{array}{l}\text { Total } \\
\text { áreas }\end{array}$} \\
\hline & \multicolumn{2}{|c|}{ Jan-Dez 2011} & \multicolumn{2}{|c|}{ Jan-Dez 2012} & \multicolumn{2}{|c|}{ Jan-Dez 2013} & \multicolumn{2}{|c|}{ Jan-Dez 2014} & \multicolumn{2}{|c|}{ Jan-Ago 2015} & \\
\hline & A1 & $\mathrm{A} 2$ & A1 & $\mathrm{A} 2$ & A1 & $\mathrm{A} 2$ & A1 & $\mathrm{A} 2$ & A1 & $\mathrm{A} 2$ & \\
\hline $\begin{array}{c}\text { Letras/ } \\
\text { Linguística }\end{array}$ & 3 & 2 & 3 & 1 & 12 & 1 & 4 & 5 & 4 & 2 & 37 \\
\hline Psicologia & 17 & 15 & 24 & 13 & 16 & 18 & 15 & 22 & 10 & 11 & 161 \\
\hline Educação & 3 & 0 & 2 & 0 & 6 & 1 & 11 & 0 & 3 & 0 & 26 \\
\hline Total-anos & \multicolumn{2}{|c|}{40} & \multicolumn{2}{|c|}{43} & \multicolumn{2}{|c|}{54} & \multicolumn{2}{|c|}{57} & \multicolumn{2}{|c|}{30} & 224 \\
\hline
\end{tabular}

Fonte: os autores 
(10), ao processamento fonológico (10) e ao movimento ocular (08). A partir dos dados, as três temáticas mais recorrentes na comunicação científico-eletrônica em relação ao campo da leitura são: a compreensão em leitura, o funcionamento cerebral durante a leitura e o processo de leitura com bilíngues. Assim, os dados parecem indicar a preocupação em torno de facetas da compreensão. Contudo, percebe-se a constituição de um grupo intermediário que parece apontar outras preocupações, tendo três deles forte relação com o processo de ensino-aprendizagem: letramento, metodologia de ensino, avaliação.

Tabela 1 - Temáticas mais recorrentes na pesquisa eletrônica da leitura

\begin{tabular}{cc}
\hline TEMÁTICAS/CATEGORIAS & ARTIGOS \\
\hline Compreensão & 22 \\
Funcionamento Cerebral & 18 \\
\hline Bilinguismo & 16 \\
Letramento & 15 \\
Metodologia de Ensino & 15 \\
Reconhecimento de Palavras & 14 \\
Avaliação & 13 \\
Atenção & 10 \\
Processamento Fonológico & 10 \\
Movimento Ocular & 08 \\
\hline
\end{tabular}

Fonte: os autores

O último passo de investigação foi o estudo da literatura eletrônica disponível por meio da elaboração de uma síntese dos artigos científicos que tinham como foco a temática em leitura mais recorrente na comunicação eletrônica. Por conseguinte, essa etapa compreendeu a apreciação dos 22 artigos eletrônicos a respeito da compreensão em leitura. As pesquisas mapeadas podem ser visualizadas na Tabela 2. Elas foram agrupadas, considerando aproximação de investigação (foco de pesquisa). Observa-se que, dentro dos estudos de compreensão, as pesquisas possuem eixos comuns, aproximados neste trabalho em seis deles especificamente: Processo de compreensão; Relação entre estratégias de leitura e compreensão; Suporte anatômico do cérebro voltado à compreensão; Variáveis relacionadas a dissociações de compreensão; Avaliação da compreensão; Melhoria da compreensão.

Tabela 2 - Foco de investigação dos 22 artigos com tema em compreensão

\begin{tabular}{|c|c|c|}
\hline PERIÓDICO(S) & REFERÊNCIA(S) & $\begin{array}{c}\text { FOCO(S) DE } \\
\text { INVESTIGAÇÃO }\end{array}$ \\
\hline $\begin{array}{l}\text { Revista de } \\
\text { Estudos da } \\
\text { Linguagem/ } \\
2237-2083\end{array}$ & $\begin{array}{c}\text { Eisenkraem } \\
\text { er e } \\
\text { Gabriel } \\
(2013)\end{array}$ & $\begin{array}{l}\text { Processo de compreensão } \\
\text { (utilização do conhecimento } \\
\text { prévio) }\end{array}$ \\
\hline $\begin{array}{l}\text { Anales de } \\
\text { Psicología/ } \\
1695-2294\end{array}$ & $\begin{array}{l}\text { Iglesias- } \\
\text { Sarmiento, } \\
\text { López e } \\
\text { Rodrígues } \\
\text { (2015) }\end{array}$ & $\begin{array}{l}\text { Processo de compreensão } \\
\text { (capacidade de memória de } \\
\text { trabalho) }\end{array}$ \\
\hline $\begin{array}{l}\text { Journal of Child } \\
\text { Psychology and } \\
\text { Psychiatry/ } \\
1469-7610\end{array}$ & $\begin{array}{l}\text { Ricketts } \\
(2011)\end{array}$ & $\begin{array}{l}\text { Processo de compreensão } \\
\text { (em relação a distúrbios } \\
\text { linguísticos) }\end{array}$ \\
\hline $\begin{array}{l}\text { Desenredo/ } \\
1808-656 \mathrm{X}\end{array}$ & $\begin{array}{l}\text { Pereira } \\
(2013)\end{array}$ & $\begin{array}{l}\text { Relação entre estratégias de } \\
\text { leitura e compreensão } \\
\text { (utilização da predição) }\end{array}$ \\
\hline $\begin{array}{l}\text { Revista do } \\
\text { GEL/ } \\
\text { 1984-591X }\end{array}$ & $\begin{array}{l}\text { Roscioli e } \\
\text { Tomitch } \\
(2014)\end{array}$ & $\begin{array}{l}\text { Relação entre estratégias de } \\
\text { leitura e compreensão } \\
\text { (utilização da inferência) }\end{array}$ \\
\hline $\begin{array}{c}\text { Letras de Hoje/ } \\
1984-7726\end{array}$ & $\begin{array}{l}\text { Tomitch } \\
\text { (2013) }\end{array}$ & $\begin{array}{l}\text { Suporte anatômico do } \\
\text { cérebro voltado à } \\
\text { compreensão (revisão } \\
\text { bibliográfica) }\end{array}$ \\
\hline $\begin{array}{c}\text { Brain Research/ } \\
0006-8993\end{array}$ & $\begin{array}{l}\text { Horowitz- } \\
\text { Kraus } \\
\text { et al (2014) }\end{array}$ & $\begin{array}{l}\text { Suporte anatômico do } \\
\text { cérebro voltado à } \\
\text { compreensão (imagens de } \\
\text { DTI) }\end{array}$ \\
\hline $\begin{array}{l}\text { Anales de } \\
\text { Psicología/ } \\
1695-2294\end{array}$ & $\begin{array}{c}\text { Canet-Juric } \\
\text { et al } \\
(2013)\end{array}$ & $\begin{array}{l}\text { Variáveis relacionadas a } \\
\text { dissociações de } \\
\text { compreensão (habilidades } \\
\text { linguístico-cognitivas) }\end{array}$ \\
\hline $\begin{array}{c}\text { Psico/ } \\
1980-8623\end{array}$ & $\begin{array}{l}\text { Corso et al } \\
\text { (2015) }\end{array}$ & $\begin{array}{l}\text { Variáveis relacionadas a } \\
\text { dissociações de } \\
\text { compreensão (modalidade } \\
\text { escolar e nível de } \\
\text { escolaridade) }\end{array}$ \\
\hline $\begin{array}{c}\text { Letras de Hoje/ } \\
1984-7726\end{array}$ & $\begin{array}{l}\text { Corso, } \\
\text { Sperb } \\
\text { e Salles } \\
(2013)\end{array}$ & $\begin{array}{l}\text { Variáveis relacionadas a } \\
\text { dissociações de } \\
\text { compreensão (ano e } \\
\text { modalidade escolares) }\end{array}$ \\
\hline $\begin{array}{c}\text { Psico/ } \\
1980-8623\end{array}$ & $\begin{array}{l}\text { Monteiro e } \\
\text { Santos } \\
(2013)\end{array}$ & $\begin{array}{l}\text { Variáveis relacionadas a } \\
\text { dissociações de } \\
\text { compreensão (modalidade } \\
\text { escolar e recurso familiar) }\end{array}$ \\
\hline $\begin{array}{l}\text { Psychology/ } \\
2152-7199\end{array}$ & $\begin{array}{l}\text { Makhoul e } \\
\text { Copti- } \\
\text { Mshael } \\
\text { (2015) }\end{array}$ & $\begin{array}{l}\text { Variáveis relacionadas a } \\
\text { dissociações de } \\
\text { compreensão (gênero textual } \\
\text { e contexto informatizado e } \\
\text { impresso) }\end{array}$ \\
\hline $\begin{array}{c}\text { Psico/ } \\
1980-8623\end{array}$ & $\begin{array}{l}\text { Alcará e } \\
\text { Santos } \\
(2013)\end{array}$ & $\begin{array}{l}\text { Avaliação da compreensão } \\
\text { (teste de Cloze com Escala } \\
\text { Likert para avaliar } \\
\text { estratégias metacognitivas) }\end{array}$ \\
\hline $\begin{array}{l}\text { Anales de } \\
\text { Psicología/ } \\
1695-2294\end{array}$ & $\begin{array}{l}\text { Cadime et } \\
\text { al } \\
(2014)\end{array}$ & $\begin{array}{l}\text { Avaliação da compreensão } \\
\text { (desenvolvimento de um } \\
\text { teste de leitura de texto } \\
\text { narrativo com questões } \\
\text { objetivas) }\end{array}$ \\
\hline $\begin{array}{l}\text { Computers and } \\
\text { Education/ } \\
0360-1315\end{array}$ & $\begin{array}{l}\text { AbuSeileek } \\
\text { (2012) }\end{array}$ & $\begin{array}{l}\text { Melhoria da compreensão } \\
\text { (com uso de tipos de notas e } \\
\text { locais em hipertextos) }\end{array}$ \\
\hline $\begin{array}{c}\text { RBLA/ } \\
1984-6398\end{array}$ & $\begin{array}{l}\text { Dias } \\
(2011)\end{array}$ & $\begin{array}{l}\text { Melhoria da compreensão } \\
\text { (criação de mapas } \\
\text { conceituais com o CMap } \\
\text { Tools) }\end{array}$ \\
\hline
\end{tabular}




\begin{tabular}{|c|c|c|}
\hline $\begin{array}{l}\text { Anales de } \\
\text { Psicología/ } \\
1695-2294\end{array}$ & $\begin{array}{l}\text { Ferrer et al } \\
\quad(2013)\end{array}$ & $\begin{array}{l}\text { Melhoria da compreensão } \\
\text { (aplicação do Ensino } \\
\text { Recíproco: atividades de } \\
\text { pré-leitura, predição, } \\
\text { resumo) }\end{array}$ \\
\hline $\begin{array}{c}\text { Paidéia/ } \\
1982-4327\end{array}$ & $\begin{array}{l}\text { Flores, } \\
\text { Pires } \\
\text { e Souza } \\
(2014)\end{array}$ & $\begin{array}{l}\text { Melhoria da compreensão } \\
\text { (institucionalização da } \\
\text { Leitura Dialógica: leitura } \\
\text { compartilhada) }\end{array}$ \\
\hline $\begin{array}{c}\text { Paidéia/ } \\
\text { 1982-4327 }\end{array}$ & $\begin{array}{c}\text { Joly e } \\
\text { Piovezan } \\
(2012)\end{array}$ & $\begin{array}{l}\text { Melhoria da compreensão } \\
\text { (utilização do Programa } \\
\text { Informatizado de Leitura } \\
\text { Estratégica) }\end{array}$ \\
\hline $\begin{array}{l}\text { Computers and } \\
\text { Education/ } \\
0360-1315\end{array}$ & $\begin{array}{l}\text { Lysenko e } \\
\text { Abrami } \\
\text { (2014) }\end{array}$ & $\begin{array}{l}\text { Melhoria da compreensão } \\
\text { (uso de dois aplicativos } \\
\text { informatizados: portfólio } \\
\text { digital e Abracadabra) }\end{array}$ \\
\hline $\begin{array}{c}\text { Letras de Hoje/ } \\
1984-7726\end{array}$ & $\begin{array}{c}\text { Naschold et } \\
\text { al } \\
(2015)\end{array}$ & $\begin{array}{l}\text { Melhoria da compreensão } \\
\text { (utilização de livros digitais } \\
\text { com Realidade Aumentada) }\end{array}$ \\
\hline $\begin{array}{c}\text { Revista de } \\
\text { Psicologia: } \\
\text { Teoria e Prática/ } \\
1980-6906\end{array}$ & $\begin{array}{c}\text { Rodrigues } \\
\text { et al } \\
(2014)\end{array}$ & $\begin{array}{l}\text { Melhoria da compreensão } \\
\text { (implantação de um } \\
\text { programa dirigido voltado à } \\
\text { metacognição) }\end{array}$ \\
\hline
\end{tabular}

Fonte: os autores

Um fato interessante a destacar é que, dos 22 artigos eletrônicos que têm como temática a compreensão, 13 foram publicados em periódicos da área de Psicologia; seis publicados em periódicos de Letras/Linguística; e três em periódicos da área de Educação. Tem-se clareza de que a área de atuação de um(a) pesquisador(a) pode estar relacionada à Letras/Linguística, e ele(a) pode publicar em periódicos vinculados à Psicologia, ou vice-versa. Contudo, como já evidenciado, os periódicos e estudos da Psicologia têm se apresentado como forte influência no campo de pesquisa de leitura e compreensão, a despeito dos de Letras/Linguística.

Além disso, com a crescente ampliação das tecnologias de estudo do cérebro, a busca de dados que referendem estudos anteriores e que possam ampliar a compreensão das relações entre mente $e$ cérebro e suas relações com a leitura é evidente na comunidade científica que busca desvelar melhor como ocorre fenômeno tão intrincado como a compreensão leitora - o que lhe é intrínseco e subjacente -, principalmente em relação às bases neurobiológicas da leitura.

Há, também, inclinação na comunicação científica para discussões epistemológicas da compreensão em torno de sua melhoria. De um lado, observamos, também, que se investigam quais habilidades e principalmente estratégias dão amparo à compreensão. E, de outro, objetiva-se proporcionar a melhoria da compreensão leitora. Outro esforço das pesquisas, com o progresso tecnológico, é em desenvolver sistemas, aplicativos, programas, dentre outros recursos, a fim de proporcionar a melhoria de habilidades e estratégias de compreensão (hiper)textual.

\subsection{Avanços e limitações no campo de compreensão: algumas reflexões}

Com o exame das investigações do processo de compreensão, ficaram evidentes muitos avanços, mas também muitas perguntas. A compreensão textual envolve diversas habilidades e processos cognitivos, funcionando em conjunto. Contudo, muitos a investigam, por exemplo, por meio do estudo de um componente-processo-habilidade isoladamente, buscando contribuir para o todo, certamente, mas o desafio de compreensão do e no conjunto permanece. Comentam-se alguns desses aspectos que direta e indiretamente se relacionam aos dados anteriormente apresentados.

Para avaliar a compreensão, por exemplo, há grande variação no aparato metodológico. Utilizam-se testes Cloze, questionários de múltipla escolha, testes de reconto. Uns utilizam textos narrativos, outros informativos. Alguns textos são curtos; outros longos. Alguns trabalhos são longitudinais; a maioria, contudo, não o é. Algumas investigações trabalham com amostras expoentes. Outras são estudos de caso. Os aspectos enumerados são fatores que podem impactar diretamente os dados e, consequentemente, sua interpretação. A natureza do teste acaba por determinar que faceta da compreensão o pesquisador está avaliando e/ou investigando. Conforme se mencionou, a compreensão textual não envolve somente uma habilidade, nem apenas um processo cognitivo. Assim, resultados podem ser tendenciosos ou equivocados. Portanto, muitas vezes, é difícil aproximar as pesquisas pelas suas conclusões. É insuficiente considerar apenas os resultados. Importa entender como o pesquisador chegou a eles.

Por essas razões, ainda analisando a avaliação da compreensão em leitura, a maioria dos 
testes foca em tarefas que, na verdade, avaliam o produto da compreensão e não a compreensão em si. Flores (2007) cita, como exemplos, os questionários de múltipla escolha (perguntas objetivas), relatos (recontos), testes Cloze. Por outro lado, há o processo. Nos protocolos verbais (relatório oral; verbalização; vocalização) e imageamento cerebral (DTIs; EEGs; ERPs; fRMls; MEGs; MRIs; rTMSs), a atenção passa do produto para o processo de compreensão, mas esses variam muito em sua forma e registro, características peculiares das tecnologias envolvidas, requerendo alta especialização - humana e tecnológica - nem sempre extensivas às necessidades urgentes da sociedade.

As pesquisas que se ativeram ao estudo da neurobiologia da leitura, isto é, às áreas cerebrais que se envolvem no processo de construção da significação textual, destacaram a participação significativa do hemisfério direito na compreensão textual. As pesquisas, com auxílio de métodos neurofisiológicos e cognitivos de pesquisa mais avançados, chamam a atenção para o trabalho dos dois hemisférios cerebrais. Desde 1990, tem-se comprovado a participação ativa do hemisfério direito no processamento linguístico, principalmente em nível de discurso (SCHERER, 2009). Sousa e Gabriel (2012) ressaltam que o hemisfério esquerdo se responsabiliza pelo processamento de ordem lexical, semântica e sintática. $\mathrm{O}$ hemisfério direito responsabiliza-se pela integração de informações textuais (proposições) com as que o leitor já tem armazenadas (conhecimento prévio), contribuindo com o processo inferencial e compreensão da linguagem conotativa. A literatura destaca que 0 hemisfério esquerdo se responsabiliza por tarefas mais especializadas, como a decodificação e a significação literal, ao passo que o direito se engaja com as mais gerais - significação contextual e interpretação de metáforas, ironias.

Em relação às pesquisas discutidas em torno de fatores relacionados ao desenvolvimento e à compreensão em leitura, como situações socioeconômicas da família do leitor (classe social e renda familiar) e condições de escolas públicas versus particulares, contribuem para as considerações apresentadas por Morais (2013): há muitas implicações ao se nascer e desenvolver-se em uma família com recursos econômicos e culturais restritos, considerando-se a sociedade da informação. Ou seja, restrições socioeconômicas que acabam por se impor ao desenvolvimento dos indivíduos, pois se relacionam diretamente com a competência e a habilidade do leitor perante tarefas de leitura. Esses aspectos envolvem léxico, conhecimento de mundo, memória, entre vários outros.

Acerca dos diferentes níveis de compreensão, as pesquisas apontaram a modalidade de escola (pública, particular) e suas condições, recursos familiares (incentivo à leitura, à cultura, investimento em materiais, livros), gênero textual, contexto de leitura (impresso, informatizado), nível de escolaridade como as principais variáveis relacionadas.

Em relação às pesquisas desenvolvidas com a finalidade de promoção da compreensão em leitura, muitas delas desenvolveram projetos que lidaram com estratégias de leitura. Igualmente, outras pesquisas comprovaram a eficiência da utilização da tecnologia no processo de ensino-aprendizagem da leitura, bem como no letramento. A esse respeito, Finger-Kratochvil (2009) destaca que há a necessidade de mudanças no processo de ensinoaprendizagem, principalmente pensando-se na formação de leitores estratégicos e no processo de letramento, o qual requer o ensino de habilidades tradicionais (texto impresso), mas também alternativas (hipertexto).

Outro argumento dos pesquisadores para a utilização das Tecnologias da Informação e Comunicação no processo educacional é que elas, muitas vezes, funcionam como instrumento motivacional. Sabe-se que muitos fatores se relacionam direta e indiretamente com o sucesso na leitura (compreensão). Um desses fatores é o emocional (ALLIENDE; CONDEMARÍN, 2005). Sabese também que estados de ânimos (sonolência, tédio, estresse) e emoções (tristeza, nervosismo, ansiedade) são reguladores da memória 
(IZQUIERDO, 2002). E se a memória não está em seu funcionamento regular, afeta a aprendizagem.

\section{Considerações Finais}

A partir da intrigante realidade que se apresenta em leitura no Brasil, como comentada ao longo do artigo, buscou-se conhecer e analisar o que a comunicação científica tem proposto por meio de estudos e pesquisas em leitura. Curiosamente, constata-se que compreensão é a temática mais recorrente e debatida dentro do campo de leitura na comunicação científica em meio eletrônico das áreas diretamente relacionadas à leitura. Todavia, outros aspectos relativos à leitura têm sido (melhor) esclarecidos e a leitura tem sido tema de parte da produção científica. $O$ avanço nos campos das diferentes ciências e das tecnologias propiciam novas possibilidades de estudo da ciência da leitura. Não resta dúvida que há ainda muito a ser entendido e desafios permanecem ao se procurar compreender a leitura de forma integral e integrada. Contudo, existe um campo de estudos que precisa ser visto, entendido e respeitado. É possível que esse seja o maior desafio no contexto acadêmico, educacional e político brasileiro. Nova pergunta de pesquisa?

\section{Referências}

ABUSEILEEK, Ali Farhan. Hypermedia annotation presentation: The effect of location and type on the EFL learners' achievement in reading comprehension and vocabulary acquisition. Computers and Education, v. 57, n. 1, p. 1281-1291, ago. 2011. Disponível em: <http://www.sciencedirect.com/science/journal/03601 315/60 >. Acesso em: 25 jan. 2017.

ALCARÁ, Adriana Rosecler; SANTOS, Acácia Aparecida Angeli dos. Compreensão de leitura, estratégias de aprendizagem e motivação em universitários. Psico, Rio Grande do Sul, v. 44, n. 3, p. 411-420, jul./set. $2013 . \quad$ Disponível em: $<$ http://revistaseletronicas.pucrs.br/ojs/index.php/revist apsico/article/view/12258>. Acesso em: 25 jan. 2017.

ALLIENDE, Felipe; CONDEMARÍN, Mabel. Leitura: teoria, avaliação e desenvolvimento. 8. ed. Porto Alegre: Artmed, 2005.
BADDELEY, Alan D. The episodic buffer: a new component of working memory? Trends in Cognitive Science, Estados Unidos, v. 4, n. 11, p. 417-423, nov. $2000 . \quad$ Disponível em: <http://old.nbu.bg/cogs/events/2002/materials/Markus/ ep_bufer.pdf >. Acesso em: 14 jan. 2017.

BADDELEY, Alan D. Working Memory: Theories, Models, and Controversies. Annual Review of Psychology, v. 63, n. 1, p. 1-29, set. 2012. Disponível em: <http://www.annualreviews.org/doi/pdf/10.1146/annur ev-psych-120710-100422>. Acesso em: 21 jan. 2017.

CADIME, Irene et al. Calibration of a reading comprehension test for Portuguese students. Anales de Psicología, Espanha, v. 30, n. 3, p. 1025-1034, out. 2014. Disponível em: $<$ http://scielo.isciii.es/scielo.php?script=sci_abstract\&p $\mathrm{id}=$ S0212-97282014003300226 >. Acesso em: 25 jan. 2017.

CAIN, Kate; OAKHILL, Jane; BRYANT, Peter. Children's Reading Comprehension Ability: Concurrent Prediction by Working Memory, Verbal Ability, and Component Skills. Journal of Educational Psychology, v. 96, n. 1, p. 31-42, abr. 2004. Disponível em: <http://isites.harvard.edu/fs/docs/icb.topic951140.files/ childrensReadingComprehensionAbilitycainOakhillBryant.pdf>. Acesso em: 11 jan. 2017.

CANET-JURIC, Lorena et al. Cognitive profile of children with low performance in reading comprehension. Anales de Psicología, Espanha, v. 29, n. 3, p. 9961005, out. 2013. Disponível em: <http://revistas.um.es/analesps/article/view/analesps. 29.3.138221 >. Acesso em: 25 jan. 2017.

CORSO, Helena Vellinho et al. Normas de desempenho em compreensão de leitura textual para crianças de $1^{\circ}$ ano a 6 ${ }^{\text {a }}$ série. Psico, Rio Grande do Sul, v. 46, n. 1, p. 68-78, jan./mar. 2015. Disponível em: $<$ http://revistaseletronicas.pucrs.br/ojs/index.php/revist apsico/article/view/16900>. Acesso em: 25 jan. 2017.

CORSO, Helena Vellinho; SPERB, Tânia Mara; SALLES, Jerusa Fumagalli de. Leitura de palavras e de texto em crianças: efeitos de série e tipo de escola, e dissociações de desempenhos. Letras de Hoje, Porto Alegre, v. 48, n. 3, p. 81-90, jan./mar., 2013. Disponível em: <http://revistaseletronicas.pucrs.br/ojs/index.php/fale/ article/viewFile/12033/8885>. Acesso em: 25 jan. 2017.

DIAS, Reinildes. Mapas conceituais mediados pelo computador: uma estratégia para aumentar a compreensão da leitura em inglês para fins específicos. Revista Brasileira de Linguística Aplicada, Belo Horizonte, v. 11, n. 4, p. 895-911, $2011 . \quad$ Disponível em: <http://www.scielo.br/pdf/rbla/v11n4/a05v11n4.pdf >. Acesso em: 25 jan. 2017.

EISENKRAEMER, Raquel Eloísa; GABRIEL, Rosângela. Falsas memórias e compreensão em leitura: possíveis interfaces. Revista de Estudos da 
Linguagem, Belo Horizonte, v. 21, n. 2, p. 151-172, jul./dez. 2013. Disponível em: $<$ http://periodicos.letras.ufmg.br/index.php/relin/article/ view/5106/4562>. Acesso em: 25 jan. 2017.

FERRER, Manuel Soriano et al. Instruction of Reading Comprehension Strategies through Reciprocal Teaching: Effects of Grouping Formats. Anales de Psicología, Espanha, v. 29, n. 3, p. 848-854, out. $2013 . \quad$ Disponível em: $<$ http://revistas.um.es/analesps/article/view/analesps. 29.3.158401>. Acesso em: 25 jan. 2017.

FINGER-KRATOCHVIL, Claudia. Estratégias para 0 desenvolvimento da competência lexical: relações com a compreensão em leitura. 2010. 677 p. Tese (Doutorado em Letras) - Universidade Federal de Santa Catarina, Santa Catarina, 2010. Disponível em: <https://repositorio.ufsc.br/bitstream/handle/12345678 9/94372/279990.pdf?sequence>. Acesso em: 12 jan. 2017.

FLORES, Onici Claro. Como avaliar a compreensão leitora. Signo, Santa Cruz do Sul, v. 32, n. 53, p. 5465, dez. 2007. Disponível em: $<$ https://online.unisc.br/seer/index.php/signo/article/vie w/123/194>. Acesso em: 12 jan. 2017.

FLORES, Eileen Pfeiffer; PIRES, Laís Fernandes; SOUZA, Carlos Barbosa Alves de. Dialogic reading of a novel for children: effects on text comprehension. Paidéia, Ribeirão Preto, v. 24, n. 58, p. 243-251, jul./dez. $2014 . \quad$ Disponível em: <http://www.scielo.br/scielo.php?script=sci_arttext\&pi $\mathrm{d}=$ S0103-863X2014000200243 >. Acesso em: 25 jan. 2017.

GABRIEL, Rosângela. Cognitive aspects and teaching implications involved in the avaliation of reading comprehension. In: SCLIAR-CABRAL, Leonor (ed.). Psycholinguistics: scientific and technological challenges. Porto Alegre: EDIPUCRS, 2010. cap. 5, p. $122-130$

HIRSCH, Eric Donald. Reading comprehension requires knowledge - of words and the world. American Educator, Estados Unidos, v. 27, n. 1, p. 10-13, 2003. Disponível em: <http://www.aft.org/sites/default/files/periodicals/Hirsc h.pdf>. Acesso em: 19 jan. 2017.

HOROWITZ-KRAUS, Tzipi et al. Involvement of the right hemisphere in reading comprehension: A DTI study. Brain Research, v. 1582, n. 25, p. 34-44, set. 2014. Disponível em: $<$ https://www.clinicalkey.com/service/content/pdf/wate rmarked/1-s2.0S0006899314007495.pdf?locale=pt_BR $>$. Acesso em: 25 jan. 2017.

IGLESIAS-SARMIENTO, Valentín; LÓPEZ, Nuria Carriedo; RODRÍGUEZ, Juan L. Rodríguez. Updating executive function and performance in reading comprehension and problem solving. Anales de Psicología, Espanha, v. 31, n. 1, p. 298-309, jan. 2015.
Disponível <http://revistas.um.es/analesps/article/view/15811> Acesso em: 25 jan. 2017.

ISRAEL, Susan E.; DUFFY, Gerald G. (Ed.). Handbook of research on reading comprehension. 2. ed. New York: The Guilford Press, 2017.

IZQUIERDO, Iván. Memória. Porto Alegre: Artmed, 2002.

JOLY, Maria Cristina Rodrigues Azevedo; PIOVEZAN, Nayane Martoni. Evaluation of the computerized strategic reading program applied to elementary school students. Paidéia, Ribeirão Preto, v. 22, n. 51, p. 83-90, jan./abr. 2012. Disponível em: <http://www.scielo.br/scielo.php?pid=S0103863X2012 $000100010 \&$ script $=$ sci arttext\&tlng $=$ en $>$. Acesso em: 25 jan. 2017

KATO, Mary Aizawa. O aprendizado da leitura. 6. ed. São Paulo: Martins Fontes, 2007.

KINTSCH, Walter. The use of knowledge in discourse processing: a construction-integration model. Psychological Review, v. 95, n. 2, p. 163-182, set. $1988 . \quad$ Disponível em: $<$ http://old.nbu.bg/cogs/personal/kokinov/COG507/Th e\%20Role\%20of\%20Knowledge\%20in\%20Discourse \%20Comprehension.pdf>. Acesso em: 12 jan. 2017.

KINTSCH, Walter; FRANZKE, Marita. The role of background knowledge in the recall of a news story. In: LORCH JR, Robert Frederick; O'BRIEN, Edward J. Sources of coherence in reading. New Jersey: Lawrence Erlbaum Associates, 1995. cap. 17, p. 321333.

KINTSCH, Walter; VAN DIJK, Teun Adrianus. Toward a model of text comprehension and production. Psychology Review, v. 85, n. 5, p. 363-394, set. 1978. Disponível em: <http://www.someya-net.com/01Tsuyaku/Reading/vanDijk_Kintsch_Model.pdf >. Acesso em: 23 jan. 2017.

KLEIMAN, Angela Bustos. Leitura: ensino e pesquisa. 4. ed. São Paulo: Pontes Editores, 2011.

KLEIMAN, Angela Bustos. Oficina de leitura: teoria e prática. 14. ed. São Paulo: Pontes Editores, 2012.

KLEIMAN, Angela Bustos. Texto e leitor: aspectos cognitivos da leitura. 12. ed. São Paulo: Pontes, 2009.

LYSENKO, Larysa V.; ABRAMI, Philip C. Promoting reading comprehension with the use of technology. Computers and Education, v. 75, n. 1, p. 162-172, jun. $2014 . \quad$ Disponível em: <http://www.sciencedirect.com/science/journal/03601 315/75>. Acesso em: 25 jan. 2017.

MAKHOUL, Baha; COPTI-MSHAEL, Thuraia. Reading comprehension as a function of text genre and presentation environment: comprehension of narrative and informational texts in a computer-assisted environment vs. print. Psychology, v. 6, n. 1, p. 10011012, jun. 2015. Disponível em: 
$<$ http://www.scirp.org/journal/PaperDownload.aspx?p aperID=57477>. Acesso em: 25 jan. 2017.

MONTEIRO, Rebecca de Magalhães; SANTOS, Acácia Aparecida Angeli. Recursos familiares e desempenho de crianças em compreensão de leitura. Psico, Rio Grande do Sul, v. 44, n. 2, p. 273-279, abr./jun. 2013. Disponível em: <http://docplayer.com.br/9945086Recursos-familiares-e-desempenho-de-criancas-emcompreensao-de-leitura.html>. Acesso em: 25 jan. 2017.

MORAIS, José. Criar leitores para uma sociedade democrática. Signo, Santa Cruz do Sul, v. 38, n. especial, p. 2-28, jul./dez. 2013. Disponível em: $<$ https://online.unisc.br/seer/index.php/signo/article/vie w/4539/3190 >. Acesso em: 11 jan. 2017.

NASCHOLD, Angela et al. Contando histórias com realidade aumentada: estratégia para promover a fluência da leitura infantil. Letras de Hoje, Porto Alegre, v. 50, n. 1, p. 138-146, jan./mar. 2015. Disponível em: <http://revistaseletronicas.pucrs.br/ojs/index.php/fale/ article/download/18394/12880>. Acesso em: 25 jan. 2017.

PEREIRA, Vera Wannmacher. Predição e compreensão na leitura de textos literários com sequências narrativas dominantes. Revista do Programa de PósGraduação em Letras da Universidade de Passo Fundo, Porto Alegre, v. 9, n. 1, p. 209-225, jan./jun. 2013. Disponível em: <http://www.upf.br/seer/index.php/rd/article/download/ 3547/2350 >. Acesso em: 25 jan. 2017.

PEARSON, P. David; CERVETTI, Gina N. Fifty years of reading comprehension theory and practice. In: PEARSON, P. David; CERVETTI, Gina N. (Ed.). Based Practices for Teaching Common Core Literacy. Teachers College Press, 2015. p. 1-24.

PEARSON, P. David; CERVETTI, Gina N. The roots of reading comprehension instruction. In: ISRAEL, Susan E.; DUFFY, Gerald G. (Ed.). Handbook of research on reading comprehension. 2. ed. New York: The Guilford Press, 2017. p. 27-55.

RICKETTS, Jessie. Reading comprehension in developmental disorders of language and communication. Journal of Child Psychology and Psychiatry, v. 52, n. 11, p. 1-44, abr. 2011. Disponível em: <http://wrap.warwick.ac.uk/39531/1/WRAP_Rickets_2 21111-ricketts_2011_pre_publication.pdf>. Acesso em: 25 jan. $20 \overline{17}$.

RODRIGUES, Maristela Bürger. Avaliando a avaliação: os documentos orientadores do ensino médio e as provas de compreensão leitora - ENEM, SAEB, PISA. 2013. 130 f. Dissertação (Mestrado em Letras) Universidade de Santa Cruz do Sul, Rio Grande do Sul, 2013. Disponível em: <http://btd.unisc.br/Dissertacoes/MaristelaRodrigues.p df>. Acesso em: 18 jan. 2015.
RODRIGUES, Marisa Cosenza et al. Intervenção em habilidades cognitivas e metacognitivas de leitura em alunos do Programa de Educação Tutorial - PET. Revista de Psicologia: Teoria e Prática, São Paulo, v. 16, n. 1, p. 181-190, jan./abr. 2014. Disponível em: <http://editorarevistas.mackenzie.br/index.php/ptp/arti cle/view/5117/4721>. Acesso em: 25 jan. 2017.

ROSCIOLI, Deise Caldart; TOMITCH, Lêda Maria Braga. The Effect of Genre Expectation on EFL Brazilian Students' Inference Generation and Reading Comprehension. Revista do GEL, São Paulo, v. 11, n. 1, p. 73-109, jan./abr. 2014. Disponível em: <https://revistadogel.gel.org.br/rg/article/view/216/277 >. Acesso em: 25 jan. 2017.

SALLES, Jerusa Fumagalli de; PARENTE, Maria Alice de Mattos Pimenta. Processos Cognitivos na Leitura de Palavras em Crianças: Relações com Compreensão e Tempo de Leitura. Psicologia: Reflexão e Crítica, v. 15, n. 2, p. 321-331, dez. 2002. Disponível em: <http://www.scielo.br/pdf/prc/v15n2/14356.pdf>.

Acesso em: 21 jan. 2017.

SCHERER, Lilian Cristine. Como os hemisférios cerebrais processam o discurso: evidências de estudos comportamentais e de neuroimagem. In: COSTA, Jorge Campos da; PEREIRA, Vera Wannmacher (Orgs.). Linguagem e Cognição: Relações Interdisciplinares. Porto Alegre: EdiPUCRS, 2009. cap. 3, p. 77-104. Disponível em: <http://www.pucrs.br/edipucrs/linguagemecognicao.pd f>. Acesso em: 13 jan. 2017.

SCLIAR-CABRAL, Leonor. Processamento bottom-up na leitura. Veredas - Revista de Estudos Linguísticos, Juiz de Fora, v. 12, n. 2, p. 24-33, 2008. Disponível em:

<http://www.ufjf.br/revistaveredas/files/2009/12/artigo 02.pdf>. Acesso em: 14 jan. 2017.

SCLIAR-CABRAL, Leonor. Sistema Scliar de Alfabetização: fundamentos. Florianópolis: Editora Lili, $2012 . \quad$ Disponível em: <http://www.saobruno.pt/pdf/escxel/Batalha\%20Outub ro_2013/SISTEMA-SCLIAR-DE-

ALFABETIZA\%C3\%87\%C3\%830-FUNDAMENTOS2012.pdf>. Acesso em: 17 jan. 2017.

SOLÉ, Isabel. Estratégias de leitura. 6. ed. Tradução Cláudia Shilling. Porto Alegre: Artmed, 1998.

SOUSA, Lucilene Bender de; GABRIEL, Rosângela. Palavras no cérebro: o léxico mental. Letrônica, Rio Grande do Sul, v. 5, n. 3, p. 3-20, jul./dez., 2012. Disponível em: <http://revistaseletronicas.pucrs.br/ojs/index.php/letro nica/article/viewFile/12244/883>. Acesso em: 23 jan. de 2017.

SOUZA, Ana Cláudia de. Leitura, metáfora e memória de trabalho: três eixos imbricados. 2004. 232 p. Tese (Doutorado em Linguística) - Universidade Federal de Santa Catarina, Florianópolis, 2004. Disponível em: <https://repositorio.ufsc.br/bitstream/handle/12345678 
9/87454/208259.pdf?sequence>. Acesso em: 16 jan.

2017.

SOUZA, Ana Cláudia de; GARCIA, Wladimir Antônio da Costa. A produção de sentidos e o leitor: os caminhos da memória. 1. ed. Florianópolis: NUP/CED/UFSC, 2012.

SPINILLO, Alina Galvão; MOTA, Márcia Maria Peruzzi Elia da; CORREA, Jane. Consciência metalinguística e compreensão de leitura: diferentes facetas de uma relação complexa. Educar em Revista, Curitiba, v. 26, n. 38, p. 157-171, set./dez. 2010. Disponível em: <revistas.ufpr.br/educar/article/view/20355/13517>. Acesso em: 12 jan. 2017.

STERnBERG, Robert. Psicologia Cognitiva. São Paulo: Cengage Learning, 2010.

SWEET, Anne Polselli; SNOW, Catherine E. Rethinking Reading Comprehension. Solving problems in the teaching of literacy. Guilford Publications, Inc., Dept. 3R, 72 Spring St., New York, NY, 2003.

TOMITCH, Lêda Maria Braga. A implementação de processos de leitura no cérebro humano: desvelando a compreensão leitora. Letras de Hoje, Porto Alegre, v. 48, n. 3, p. 309-315, jul./set. 2013. Disponível em: $<$ http://revistaseletronicas.pucrs.br/fo/ojs/index.php/fal e/article/download/12523/9910>. Acesso em: 25 jan. 2017

VAN DIJK, Teun Adrianus; KINTSCH, Walter. Strategies of discourse comprehension. New York: Academic Press, $\quad 1983 . \quad$ Disponível em: <http://www.discourses.org/OldBooks/Teun\%20A\%20 van\%20Dijk\%20\%26\%20Walter\%20Kintsch\%20\%20Strategies\%20of\%20Discourse\%20Comprehensi on.pdf>. Acesso em: 14 jan. 2017.

WEBQUALIS. [Documento de área 2013]. 2015. Disponível em: $<$ http://qualis.capes.gov.br/webqualis/principal.seam>. Acesso em: 26 maio 2017.

\section{COMO CITAR ESSE ARTIGO}

GIRALDELLO, Ademir Paulo; FINGER-KRATOCHVIL, Claudia. A pesquisa científica no campo da compreensão em leitura: um estudo analítico da produção acadêmica. Signo, Santa Cruz do Sul, v. 43, n. 77, p. 2-18, jul. 2018. ISSN 1982-2014. Disponível em: <https://online.unisc.br/seer/index.php/signo/article/view/12239>. Acesso em: doi: http://dx.doi.org/10.17058/signo.v43i77.12239. 